\title{
Medial Geniculate Lesions Block Amygdalar and Cingulothalamic Learning-Related Neuronal Activity
}

\author{
Amy Poremba ${ }^{1}$ and Michael Gabriel ${ }^{2}$ \\ ${ }^{1}$ Department of Psychology and Institute for Neuroscience, Univsity of Texas, Austin, Texas 78712, and ${ }^{2}$ Department of \\ Psychology and Beckman Institute, University of Illinois, Urbana, Illinois 61801
}

This study assessed the role of the thalamic medial geniculate (MG) nucleus in discriminative avoidance learning, wherein rabbits acquire a locomotory response to a tone [conditioned stimulus (CS)+] to avoid a foot shock, and they learn to ignore a different tone (CS-) not predictive of foot shock. Limbic (anterior and medial dorsal) thalamic, cingulate cortical, or amygdalar lesions severely impair acquisition, and neurons in these areas develop training-induced activity (TIA): more firing to the CS+ than to the CS-. MG neurons exhibit TIA during learning and project to the amygdala. The MG neurons may supply afferents essential for amygdalar and cingulothalamic TIA and for avoidance learning. To test this hypothesis, bilateral electrolytic or excitotoxic ibotenic acid MG nuclear lesions were induced, and multiunit recording electrodes were chronically implanted into the anterior and posterior cingulate cortex, the anterior-ventral and medial-dorsal thalamic nuclei, and the basolateral nucleus of the amygdala before training. Learning was severely impaired and TIA was abolished in all areas in rabbits with lesions. Thus learning and TIA require the integrity of the $M G$ nucleus. Only damage in the medial MG division was significantly correlated with the learning deficit. The lesions abolished the sensory response of amygdalar neurons, and they attenuated (but did not eliminate) the sensory response of cingulothalamic neurons, suggesting the existence of extra geniculate sources of auditory transmission to the cingulothalamic areas.

Key words: limbic thalamus; cingulate cortex; amygdala; learning; instrumental conditioning; anterior ventral nucleus; medial dorsal nucleus
There is currently a great interest in the neural circuitry underlying aversively motivated learning (for review, see Davis, 1992; Gabriel, 1993; Lennartz and Weinberger, 1994; LeDoux, 1995; McGaugh et al., 1995; Maren and Fanselow, 1996). A central role of amygdalar neurons is indicated by findings that amygdala lesions impair the acquisition of conditioned immobility (LeDoux et al., 1988; Fanselow and Kim, 1994; LeDoux, 1995), autonomic responding (Blanchard and Blanchard, 1972; Spevack et al., 1975; Kapp et al., 1979; Gentile et al., 1986; Iwata et al., 1986; Helmstetter, 1992) and fear-potentiated startle behavior (Davis, 1986, 1992; Hitchcock and Davis, 1987; Sananes and Davis, 1992). Also, amygdalar neurons exhibit associative, training-induced activity (TIA) during Pavlovian conditioning (Umemoto and Olds, 1975; Applegate et al., 1982; Pascoe and Kapp, 1985; Nishijo et al., 1988; Muramoto et al., 1993; McEchron et al., 1995; Quirk et al., 1995).

An involvement of the medial geniculate (MG) nucleus in aversively motivated learning is indicated by the observation of TIA in the medial division of the MG nucleus (MGm) (Olds et al., 1972; Gabriel et al., 1975; Gabriel et al., 1976; Ryugo and Weinberger, 1978; Birt and Olds, 1981; Weinberger, 1982; Edeline, 1990; Edeline and Weinberger, 1992; McEchron et al., 1995), and by impaired conditioning in animals with MG lesions (Iwata et al., 1986; Jarrell et al., 1986; LeDoux et al., 1986a,b; McCabe et al., 1993).

\footnotetext{
Received June 10, 1997; revised Aug. 20, 1997; accepted Aug. 22, 1997.

This work was supported by National Institutes of Health Grant NS26736 and by National Science Foundation Grant BIR9504842 to M.G.

Correspondence should be addressed to Dr. Michael Gabriel, University of Illinois, Beckman Institute, 405 N Mathews, Urbana, IL 61801.

Copyright (C) 1997 Society for Neuroscience $0270-6474 / 97 / 178645-11 \$ 05.00 / 0$
}

Amygdalar and MG neurons are involved in aversively motivated instrumental conditioning processes, as well as in classical aversive conditioning. TIA develops rapidly in these areas during discriminative avoidance learning in rabbits (Gabriel et al., 1975, 1976, 1991b; Maren et al., 1991) and amygdalar lesions severely impair behavioral acquisition (Poremba and Gabriel, 1997).

Results of neuronal recording and lesion studies demonstrate a critical involvement of cingulate cortex and related limbic areas [the anterior and medial dorsal (MD) nuclei] of the thalamus in discriminative avoidance learning (for review, see Gabriel., 1993; see also Kubota et al., 1996). Intriguingly, cingulothalamic TIA and behavioral learning are blocked in rabbits with bilateral amygdalar lesions (Poremba and Gabriel, 1997), suggesting that amygdalar efferents are essential for the cingulothalamic TIA.

Amygdalar TIA develops rapidly, at the outset of training, whereas TIA in particular cingulothalamic areas develops gradually, suggesting that the amygdalar efferents are needed to initiate more gradual learning-relevant cingulothalamic coding. It has been proposed (Poremba and Gabriel, 1997) that the rapid amygdalar TIA may represent the acquisition of conditioned fear, whereas the more gradual cingulothalamic TIA development may reflect changes underlying acquisition of the instrumental behavior.

Direct projections of MG neurons to the amygdala and the occurrence of MG nuclear TIA raise the possibility that MG nuclear sensory and/or associative coding is essential for amygdalar and cingulothalamic TIA. If true, lesions of the MG nucleus will block amygdalar and cingulothalamic TIA, as well as discriminative avoidance learning. The present study tested this hypothesis. 


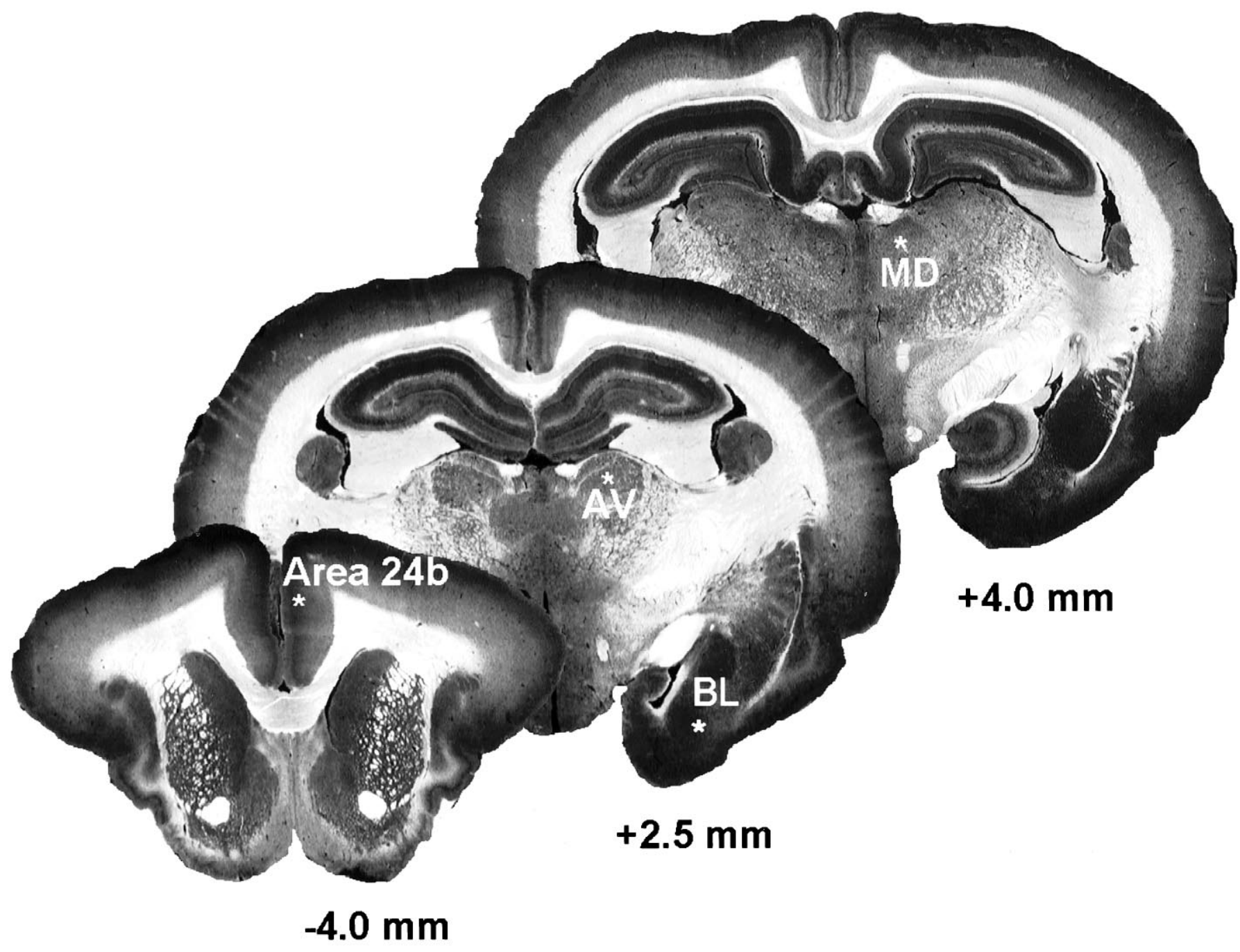

Figure 1. Recording sites for anterior cingulate cortex (Area 24b), the AV thalamic nucleus, the BL amygdalar nucleus, and the MD thalamic nucleus. The sites are indicated by the white asterisks, in three coronal sections at the indicated levels in millimeters anterior (negative value) and posterior ( positive values) to begma.

Preliminary results have been reported in abstract form (Poremba and Gabriel, 1993).

\section{MATERIALS AND METHODS}

Subjects. The subjects were 29 male New Zealand White rabbits weighing $1.5-2.0 \mathrm{~kg}$ on delivery to the laboratory and maintained on ad libitum water and one cup of rabbit chow daily. It has been found that mild restriction of food intake maintains good health and prevents obesity.

Surgical implantation of recording electrodes. After a minimum of 1 week for adaptation to living cages, each rabbit underwent surgery for chronic intracranial implantation of micro electrodes for recording of multiunit neuronal activity. Surgical anesthesia was induced by subcutaneous injection $(1 \mathrm{ml} / \mathrm{kg}$ of body weight) of a solution containing 60 $\mathrm{mg} / \mathrm{ml}$ of ketamine $\mathrm{HCl}$ and $8 \mathrm{mg} / \mathrm{ml}$ of xylazine, followed by hourly injections of $1 \mathrm{ml}$ of the solution.

Each rabbit was placed in a Kopf stereotaxic rabbit head clamp. Six intracranial recording electrodes were lowered through burr holes (diameter, $0.5 \mathrm{~mm}$ ) drilled in the skull over the target sites. The electrodes were made with stainless steel insect pins $(00$; bare shaft diameter, $0.28-0.30 \mathrm{~mm}$ ) insulated with Epoxylite. The recording surfaces were made by removing insulation from the tip of the pin. The recording surface lengths ranged from 10 to $50 \mu \mathrm{m}$, from tip to insulation, and electrical impedances ranged from 500,000 $\Omega-2 \mathrm{M} \Omega$. Miniature cylindrical Teflon electrode guides (length, $2.5 \mathrm{~mm}$; diameter, $1.5 \mathrm{~mm}$ ) impaled on bare pins were positioned over each burr hole and affixed to the skull using dental acrylic. The pins were removed after the dental acrylic was set. The recording electrodes were slowly advanced to the targets by press fitting them through the holes in the Teflon guides. Wires were presoldered to the electrodes and to each of six contact pins in a nine-pin Amphenol connector, which was also affixed to the skull with dental acrylic and stainless steel machine screws. An additional stainless steel machine screw threaded into the frontal sinus and connected to one of the Amphenol contacts served as the recording reference electrode.

Neuronal activity was monitored acoustically and with an oscilloscope during electrode advancement as an aid to electrode placement. The electrodes were not attached to the manipulator, greatly reducing the risk that slight movements of the rabbit (e.g., attributable to respiration) would damage cells. The recording sites are shown in coronal sections of the rabbit brain in Figure 1. The stereotaxic coordinates (Girgis and Shih-Chang, 1981) were as follows: anterior-ventral (AV) nucleus: anteroposterior (AP), $2.0 \mathrm{~mm}$; lateral, $(\mathrm{L}), \pm 2.3 \mathrm{~mm}$, and ventral $(\mathrm{V}), 7.5$ $\mathrm{mm}$; medial-dorsal (MD) nucleus, AP, $4.6 \mathrm{~mm}$; L, $\pm 1.5 \mathrm{~mm}$; and V, 8.0 $\mathrm{mm}$; anterior cingulate cortex (Brodmann's area 24b): AP, $-4.0 \mathrm{~mm}$; L, $\pm 0.8 \mathrm{~mm}$; and $\mathrm{V}, 3.0 \mathrm{~mm}$; and basolateral (BL) amygdalar nucleus: $\mathrm{AP}$, $1.5 \mathrm{~mm}$; L, $\pm 5.0 \mathrm{~mm}$; and $\mathrm{V}, 15.2 \mathrm{~mm}$.

Lesions. Bilateral electrolytic lesions of the MG nucleus were induced during surgery, using electrodes made from stainless steel insect pins coated with Epoxylite insulation. The insulation was removed from the 
tips to uncover $0.80-0.90 \mathrm{~mm}$ of the metal. The lesion electrodes were stereotaxically positioned in the target sites, and a $1.5 \mathrm{~mA}$ cathodal DC current was passed at each site for $30 \mathrm{sec}$. The target sites (six per hemisphere) were AP, $6.5 \mathrm{~mm} ; \mathrm{L}, \pm 5.6 \mathrm{~mm} ; \mathrm{V}, 12.5,13.5$, and $14.5 \mathrm{~mm}$; and AP, $7.5 \mathrm{~mm} ; \mathrm{L}, \pm 5.5 \mathrm{~mm}$; and $\mathrm{V}, 12.5,13.5$, and 14.5. These lesion coordinates were selected to produce severe damage in three divisions (dorsal, medial, and ventral) of the MG nucleus and in the suprageniculate nucleus.

Fiber-sparing lesions were also made using the excitotoxin ibotenic acid to provide control for the possibility that any observed effects of the electrolytic lesions were attributable to disruption of fibers passing through but not originating in the damaged area. One-half microliter of an ibotenic acid solution $(5 \mathrm{mg} / \mathrm{ml}$ ibotenic acid dissolved in sterile $0.9 \%$ saline) was infused bilaterally at a rate of $0.8 \mu \mathrm{l} / \mathrm{min}$, using a 28 gauge cannula attached via oil-filled polyethylene tubing to a $5 \mathrm{cc}$ syringe held in an infusion pump. After injection, the cannula remained in the injection site for $15 \mathrm{~min}$. Four rabbits received sham lesions, consisting of injection with sterile $0.9 \%$ saline.

Collection of neuronal data. During behavioral testing the neuronal records were fed into field effect transistors (FETs), which served as high-impedance source followers attached to a connector, which mated with the nine-pin connector affixed to the skull, about $2.5 \mathrm{~cm}$ from the brain recording sites. The FET outputs, fed via a shielded cable for each recording channel, were split, one limb entering single-ended preamplifiers with bandwidth appropriate for unit recording (gain, 40,000; halfamplitude cutoffs, 500 and $8000 \mathrm{~Hz}$ ), the other limb entering preamplifiers for recording of field potentials (gain, 8000; half-amplitude cutoffs, 0.2 and $60 \mathrm{~Hz}$ ). The unit activity was subjected to a second stage of active bandpass filtering (half-amplitude cutoffs, 600 and $8000 \mathrm{~Hz}$; roll-off, 18 $\mathrm{dB} /$ octave) to remove all slower frequencies while preserving extracellular neuronal spikes. The filter outputs were fed to Schmitt triggers, which produced an $80 \mu \mathrm{sec}$ square wave pulse when spike-induced input voltages exceeded a preset threshold. The triggering thresholds were automatically adjusted to yield a mean pulse rate of $95-165 / \mathrm{sec}$. Using this criterion, the largest three or four spikes per record were sampled. This criterion, established by past experience, affords a good compromise between the need to restrict the number of cells monitored while obtaining robust and repeatable multiunit discharge profiles.

The bandpass filter outputs were half-wave-rectified and integrated (see Buchwald et al., 1973). The time constants for the rise and fall of the integrators were 15 and $75 \mathrm{msec}$, respectively. The Schmitt trigger data indicated the discharge frequency of the largest neuronal spikes. As an electronically derived integral of the entire spike record, the integrated activity assesses the firing of all neurons in the range of the electrode, including activity below the triggering thresholds used for spike frequency sampling. Of course, the weighting of the contribution of a given neuron to the sampled integral will depend on a variety of factors such as its size and distance from the recording electrode.

The integrated activity and spike frequency measures are complementary. Given the breadth of the sample taken and the smoothing effect of the integration, the integrated activity is often more sensitive to experimental manipulations than is spike frequency. In contrast, the small number of cells sampled with the spike frequency measure means that this measure approximates extracellular single-unit recording. Moreover, the smoothing effect renders the temporal profiles of histograms constructed from integrated activity less accurate than spike frequency histogram profiles. Only the spike frequency histograms provide highly veridical estimates of latencies and durations of particular neuronal response features.

Spike frequency as indicated by Schmitt trigger output was accumulated, and the integrator outputs and field potentials were digitized in each of $10010 \mathrm{msec}$ intervals, 30 intervals $(0.3 \mathrm{sec})$ before and 70 intervals $(0.7 \mathrm{sec})$ after conditioned stimulus (CS) onset. A digital value was stored for each measure and electrode, every $10 \mathrm{msec}$ during the sampling interval. Individual trial data were stored on digital magnetic tape.

Several computer-, and experimenter-controlled methods were used to exclude neuronal data containing movement-related artifacts (see Gabriel et al., 1983; Kubota and Gabriel, 1995).

Avoidance training. After a $7-10$ d postsurgical recovery period the rabbits received discriminative avoidance training, which was administered while they occupied a large activity wheel designed for conditioning of small animals (Brogden and Culler, 1936). The wheel was contained in a shielding chamber in a room adjacent to the room that housed the equipment for data collection. An exhaust fan and a speaker in the chamber produced a masking noise $\left(70 \mathrm{~dB}\right.$ re: $\left.20 \mathrm{~N} / \mathrm{m}^{2}\right)$ throughout training. The CS+ and CS- were pure tones $(0.5 \mathrm{sec}$ duration, 1 or $8 \mathrm{kHz}$ ) played through a loudspeaker attached to the chamber ceiling directly above the wheel. The tone stimuli $\left(85 \mathrm{~dB}\right.$ re: $\left.20 \mathrm{~N} / \mathrm{m}^{2}\right)$ had a rise time of $3 \mathrm{msec}$. Assignment of the tones as $\mathrm{CS}+$ or $\mathrm{CS}-$ was counterbalanced.

During avoidance training the onset of the CS+ was followed after five seconds by the foot shock, unconditional stimulus (US; a constant current 1.5-2.5 mA, delivered through the grid floor of the wheel). Behavioral responses were defined as locomotion-induced wheel rotation of $2^{\circ}$ or more. The US was terminated by behavioral responses produced by foot shock. The maximum duration of the US was $1 \mathrm{sec}$. Behavioral responses performed within the interval from CS + onset to US onset prevented the administration of the foot shock US. Such responses were defined as avoidance responses. The negative conditional stimulus, $\mathrm{CS}-$, presented equally as often as the CS+, was not followed by the US. The CS + and CS- were presented 60 times in each training session, in an irregular sequence. The interval from the end of a trial to tone onset for the next trial was $8,13,18$, or $23 \mathrm{sec}$. These values occurred in an irregular sequence. (The end of a trial was the termination of the $5 \mathrm{sec}$ period after tone onset or termination of wheel rotation when locomotion occurred). Wheel rotation responses during the intertrial interval reset the intertrial interval.

Although a minimal wheel turn response of $2^{\circ}$ was sufficient to be scored as a response, the learned avoidance responses of the rabbits were invariably of much greater magnitude, consisting of one or more steps in the wheel. The average magnitude of the avoidance response in trained rabbits is about $400^{\circ}$ of wheel rotation.

Each rabbit received two "pretraining" sessions before avoidance training. In the first pretraining session, 60 presentations of each tone without the foot shock US were given, with the same timing and ordering as during training. The same schedule of tone presentations with the addition of explicitly unpaired US presentations (see Rescorla, 1967) were given in the second pretraining session. In this session the US was not presented during a tone or within three seconds before or after a tone presentation. The number and trial distribution of US presentations during this session were the averages, for 100 rabbits, of the number and distribution of US presentations received during the first session of avoidance training. This pretraining session provided baseline data for detecting associative neural and behavioral changes induced later by the explicit pairing of the CS with the US during training.

Twenty-four hours after the second pretraining session, the rabbits received avoidance training (60 CS + and $60 \mathrm{CS}-$ trials) in which the CS + was followed by the US on nonresponse trials but the US never followed the CS-. Training was given at approximately the same time each day until a behavioral criterion was reached. The criterion required that the percentage of trials with avoidance responses exceed the percentage of CS - trials with behavioral responses by $\geq 60 \%$, in two consecutive daily training sessions. Past studies have shown that this criterion yields asymptotic discriminative performance (i.e., performance levels yielded by this criterion are not exceeded if further training is given). Also noted was the session of the first significant (FS) behavioral discrimination, defined as the first training session in which the percentage of avoidance responses to the $\mathrm{CS}+$ exceeded the percentage of responses to the CS- by $25 \%$ or more. This value approximates the minimum value required to produce a significant $\chi^{2}(p<0.05)$ for a difference between correlated proportions (Walker and Lev, 1953, p 101). Training was terminated for rabbits that failed to perform the FS behavioral discrimination after seven $d$ of training. Training was also terminated for rabbits that reached FS behavioral discrimination within $7 \mathrm{~d}$ of training but failed to attain criterion after fifteen training sessions.

Analysis of data. Because varied numbers of training sessions were required for criterion attainment, the analysis of the neuronal data were restricted to four stages of training common to all rabbits. Each stage was represented by the data of a single training session. The stages were (1) pretraining with explicitly unpaired presentations of the conditional stimuli and US (pretraining); (2) the first session of avoidance training (first exposure); (3) the session of the FS behavioral discrimination (first significant discrimination); and (4) the session in which the acquisition criterion was attained (criterion). Behavioral and neuronal data for the FS discrimination session of rabbits that did not reach FS behavioral discrimination were obtained from the training day that corresponded to the average number of training sessions required by controls to attain the FS behavioral discrimination. Data of the last session of training were used as criterial data for rabbits that did not reach criterion. 


\section{Electrolytic Ibotenic Acid Lesions Lesions}
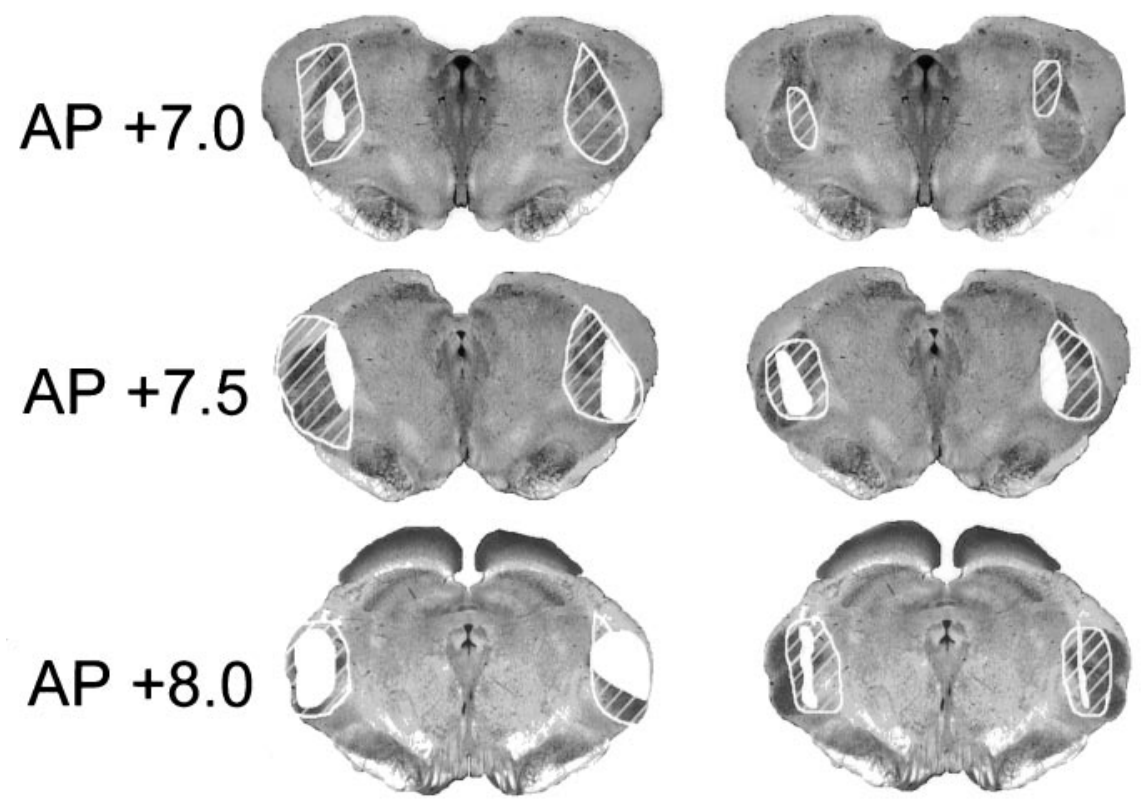

Figure 2. Largest (hatched areas) and smallest ( filled areas) bilateral electrolytic and ibotenic acid lesions in four coronal sections at the indicated levels in millimeters posterior to bregma.

\section{$\mathrm{AP}+8.5$}

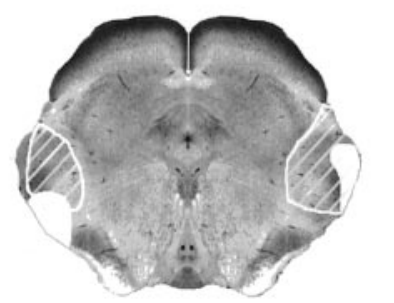

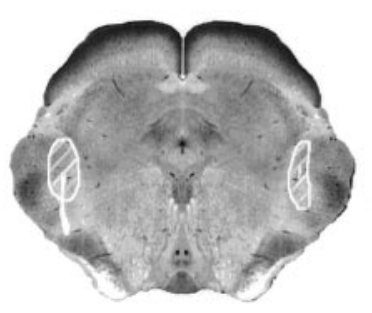

Spike frequency and integrated unit activity values were sampled in 100 consecutive $10 \mathrm{msec}$ intervals, 30 pre-CS intervals (before CS onset) and 40 post-CS intervals (after CS onset). A mean pre-CS baseline value was subtracted from activity values in each 40 post-CS intervals. The baseline mean was calculated by averaging the activity values in the 30 pre-CS $10 \mathrm{msec}$ intervals.

The resultant normalized activity scores and behavioral data were submitted to factorial, repeated measures ANOVA using the $2 \mathrm{~V}$ program (BMDP Statistical Software). The $\alpha$ level for all testing was set at 0.05 . The analyses had a between-subject factor, groups (lesion and control), and orthogonal repeated measures factors of training stage (four stages as described above), stimulus (two levels, $\mathrm{CS}+$ and $\mathrm{CS}-$ ), and, for the neuronal data, 40 consecutive $10 \mathrm{msec}$ post-CS recording intervals. Correction of the $F$ test because or disconformity of the data with the sphericity assumption of these analyses was performed as needed following the procedure of Huynh and Feldt (1976). Factors yielding significant overall $F$ ratios were further analyzed using simple effect tests following procedures described by Winer (1962, Chap 7).

As in other studies of this project, occurrences of higher-order threeand four-way interactions in the ANOVA are predicted. Discriminative training-induced activity in the target areas is expected (i.e., a different profile of the neuronal discharge in response to the CS+ than to the CS - ). It is also expected that the discriminative TIA will be influenced by the lesions, and that these differences may occur in particular post-CS intervals and during particular stages of behavioral acquisition. The analyses of spike frequency and integrated unit activity yielded the same significant relationships. To avoid redundancy, only the spike frequency data are presented here.

Histology. After training, euthanasia was administered via an overdose of sodium pentobarbital followed by transcardiac perfusion with normal saline and $10 \%$ formalin. The brains were frozen and sectioned at $40 \mu \mathrm{m}$, and the sections containing the electrode tracks were photographed while still wet (Fox and Eichman, 1959). Every fifth section through the lesion area was photographed, and every section through the lesion was subjected to a metachromatic Nissl and myelin stain (Donovick, 1974).

Lesions and the experimental groups. The determination of the boundaries of the MG nuclear divisions was based on the work of Winer and Morest (1983) for cats, as well as mappings used in recent studies with rabbits and rats (LeDoux et al., 1985; McCabe et al., 1993). To quantify lesion size, the number of $0.25 \mathrm{~mm}$ grid squares covering the damaged portion of the four divisions of the MG nucleus was counted bilaterally in each of seven coronal brain sections spaced $0.5 \mathrm{~mm}$ apart from 6.5 to $9.5 \mathrm{~mm}$ posterior to bregma (Girgis and Shih-Chang, 1981). The average percentage of damaged relative to spared MG nuclear tissue over sections and hemispheres was calculated for each rabbit. The average damage score for rabbits with electrolytic lesions was $53.7 \%$ (range, $33.25-74 \%$ ). The average damage score for the separate divisions of the $\mathrm{MG}$ nucleus for the rabbits with electrolytic lesions were medial division, 49\%; dorsal division, $64.9 \%$; ventral division, $40.33 \%$; and suprageniculate nucleus, $60.56 \%$. The average score for rabbits with ibotenic acid lesions was $22.68 \%$ (range, $14.25-44.25 \%$ ). The average damage scores for each MG nuclear division for the rabbits with ibotenic acid lesions were medial division, $28.43 \%$; dorsal division, $35.58 \%$; ventral division, $11.14 \%$; and suprageniculate nucleus, $15.57 \%$. The largest and smallest lesions are illustrated in Figure 2.

Control data for the electrolytic lesions were obtained from rabbits $(n=9)$ serving as subjects in concurrent studies performed with procedures identical to those just described. These rabbits had surgery for recording electrode placement but no lesions. Four rabbits given sham (saline) injections and recording electrodes served as controls for assessment of the behavioral effects of the ibotenic acid lesions. Control data for assessment of the effects of the lesions on amygdalar training-related neuronal activity were obtained from rabbits in a previous study (Maren et al., 1991). Although there was a substantial time gap between the 


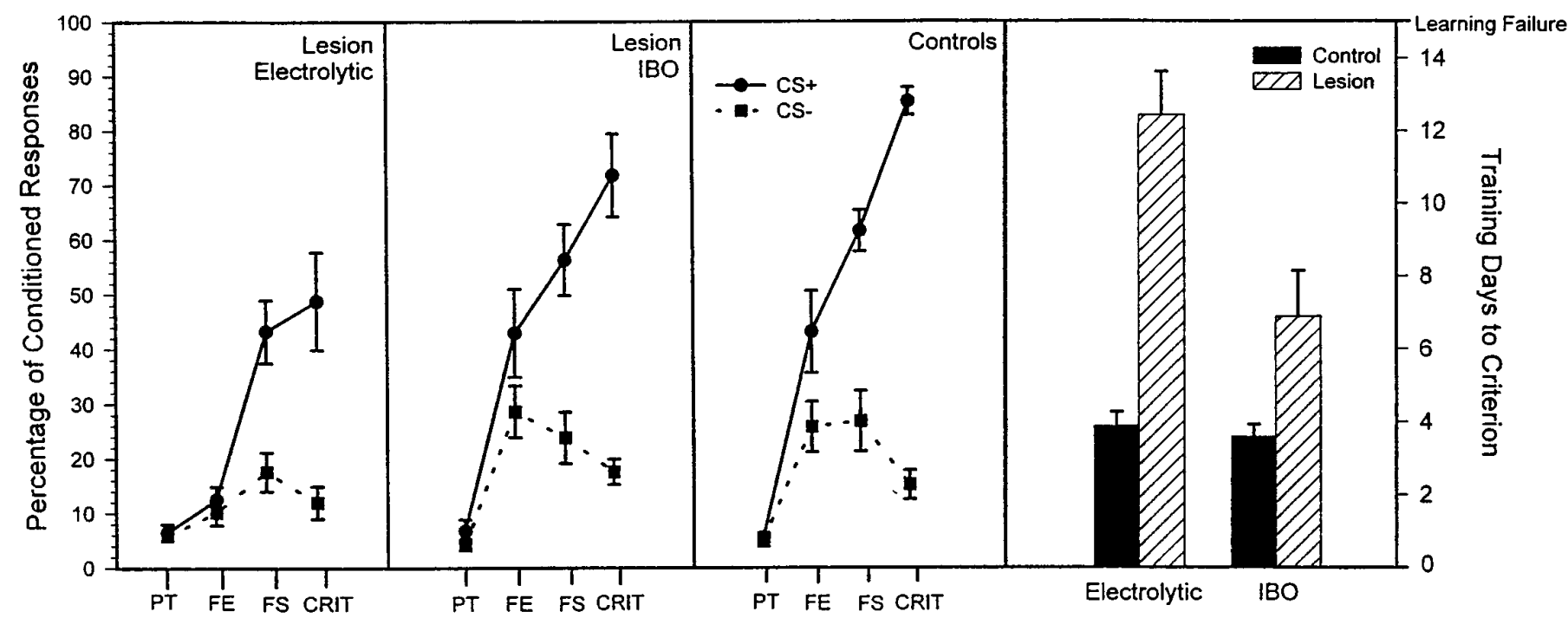

Figure 3. Percentage of conditioned avoidance responses (left $y$ axis) performed in response to the CS+ and CS - is plotted for the electrolytic lesion group (left panel), the ibotenic acid lesion group (second panel from left), and the control group (third panel from left). The right panel shows the number of training sessions (days) required for attainment of the criterion of behavioral acquisiiton. The plotted values in the right panel refer to the right $y$-axis. Filled bars represent the control groups, and hatched bars represent electrolytic and Ibotenic acid lesion groups. $P T$, Pretraining; $F E$, session of the first exposure to paired CS+ and US training trials; FS, session in which the first significant behavioral discrimination occurred; CRIT, session in which the criterion was attained.

collection of these control data and the present study, the amygdalar changes observed in 1991 were replicated very recently with the same procedures (Freeman et al., 1997).

As indicated by the damage scores, the ibotenic acid lesions were not as large as were the electrolytic lesions. Larger ibotenic acid injections made in an attempt to equate the lesions in the two groups proved to be lethal.

Distribution of neuronal records. A total of 67 neuronal records from the designated recording sites was obtained. The numbers of records per area in each group were as follows: control group: AV nucleus, 8; MD nucleus, 5; anterior cingulate cortex, 7; BL amygdalar nucleus, 6; electrolytic lesion group: AV nucleus, 8; MD nucleus, 9; area 24, 13; BL nucleus, 6; and ibotenic acid lesion group: AV nucleus, 5. AV thalamic neuronal recordings included in the control group were used for comparison with $\mathrm{AV}$ thalamic data of both electrolytic lesion and ibotenic acid lesion groups. The analyses of neuronal data of rabbits with ibotenic acid lesions did not include recordings from the anterior cingulate cortex, medial-dorsal nucleus, or basolateral amygdalar nucleus because of the small number of records obtained in these areas.

\section{RESULTS}

\section{Behavioral data: electrolytic lesions Behavioral acquisition}

The average numbers of training sessions required for criterion attainment were 12.44 and 3.89, respectively, for rabbits with electrolytic lesions and controls (Fig. 3, right panel). This difference yielded a significant main effect of the group factor $[p<$ $\left.0.0001 ; F_{(1,16)}=46.59\right]$ in the ANOVA. Rabbits that failed to attain the behavioral criterion received a score of 15 , which equaled the number of daily training sessions administered before declaring failure to learn. The behavioral criterion was not reached by five of the nine rabbits with lesions. The remaining four rabbits attained the criterion in 5, 9, 11, and 12 training sessions, respectively. All rabbits in the control group reached the criterion.

\section{Avoidance responses during acquisition}

The lesions reduced the frequency of avoidance responses during training as indicated by results of analyses of conditioned re- sponse frequency in various stages of behavioral acquisition (Fig. 3 , first and third panels from left). The factors analyzed were group (lesion and control), training stage (four levels: pretraining, first exposure, first significant discrimination, and criterion), and stimulus (two levels: $\mathrm{CS}+$ and $\mathrm{CS}-$ ). A significant interaction of the group, training stage, and stimulus factors $\left[p<0.002 ; F_{(3,48)}\right.$ $=5.89$ ] followed by simple effect tests showed that the groups did not differ in terms of the incidence of the infrequent locomotory responses during pretraining. However, the average percentage of avoidance responses performed by rabbits with lesions was significantly reduced relative to that of controls, during the first exposure to conditioning $(p<0.01)$, the session of first significant discrimination $(p<0.05)$, and during criterion attainment $(p<$ 0.01). The lesions did not significantly affect the incidence of responses to the $\mathrm{CS}-$.

\section{Other behavioral measures}

There were no significant effects of the lesions on the mean latency and duration of avoidance responses, mean latency and duration of escape responses to the shock US, or mean number of intertrial responses.

\section{Behavioral data: ibotenic acid lesions}

\section{Rate of behavioral acquisition}

Although the ibotenic acid lesions were generally smaller than the electrolytic lesions (Fig. 2), they were nevertheless associated with impaired discriminative avoidance learning. The average number of training sessions required for criterion attainment in rabbits with ibotenic acid lesions (6.89) was significantly greater than the average number of sessions required for criterion attainment in controls (3.59; Fig. 3, right panel), as indicated by a significant main effect of the group factor of the analysis $\left[p<0.01 ; F_{(1,19)}=\right.$ $8.35)$. One of the rabbits with ibotenic acid lesions and none of the rabbits in the control group failed to attain the behavioral criterion. 


\section{Avoidance responses during acquisition}

The ibotenic acid lesions were associated with a lessened frequency of avoidance response performance during acquisition. This was indicated by a significant interaction of the group and stimulus factors $\left[p<0.03 ; F_{(1,15)}=6.64\right]$ in the four-factor repeated measure ANOVA as described above. Simple effect tests demonstrated that the average percentage of avoidance responses to the CS + performed by rabbits with ibotenic acid lesions over all training stages was significantly less than the percentage of responses performed by controls $(p<0.05)$. No significant differences were found for responses to the $\mathrm{CS}-$.

\section{Other behavioral measures}

There were no significant effects of the lesions on the mean latency and duration of avoidance responses, mean latency and duration of escape responses performed in response to the foot shock US, or the mean number of intertrial responses.

\section{Lesions and behavior: correlational analyses}

A clear relationship between the amount of lesion-related damage in specific divisions of the MG nucleus and behavioral performance was found during the session of criterion attainment in the rabbits with lesions. The overall damage scores (including all MG nuclear damage in rabbits with electrolytic and ibotenic acid lesions) were not significantly predictive of behavioral performance $(r=-0.40)$. A significant correlation was found for avoidance response performance and the damage scores for the medial division of the MG nucleus $(r=-0.98 ; P<0.01)$. Correlation of performance with damage scores of the dorsal, ventral, and suprageniculate divisions of the MG nucleus were not significant ( $r=-0.40,-0.38$, and -0.28 , respectively).

\section{Neuronal activity and electrolytic lesions}

Sensory neuronal discharges before training

To assess the effects of the lesions on auditory neural transmission, independently of effects on training-induced activity, analyses were performed separately on the elicited discharges recorded during the first pretraining session, in which tones only and no foot shock presentations were given. Significant main effects of the group factor indicated that the average elicited neuronal discharge magnitudes in rabbits with lesions were significantly reduced, relative to the discharges of the control group, in the AV nucleus $\left[p<0.05 ; F_{(1,14)}=4.63\right]$ and in the BL nucleus of the amygdala $\left[p<0.04 ; F_{(1,11)}=5.92\right]$. The neuronal discharges recorded in the anterior cingulate cortex and the MD nucleus were not significantly affected by the lesions.

\section{Elicited neuronal discharges during training}

The lesions reduced the magnitude of CS-elicited neuronal discharges during training. This was indicated by significant main effects of the group factor in the analyses of the data of all of the monitored areas [AV nucleus, $p<0.01 ; F_{(1,14)}=26.21$; MD nucleus, $p<0.03 ; F_{(1,12)}=7.06$; anterior cingulate cortex, $p<$ $0.05 ; F_{(1,18)}=4.86$; BL nucleus of the amygdala, $p<0.03 ; F_{(1,10)}$ $=8.76]$. In addition, there occurred significant interactions of the group and recording interval factors [AV nucleus, $p<0.01$; $F_{(39,546)}=4.93$; MD nucleus, $p<0.01 ; F_{(39,468)}=2.88$; anterior cingulate cortex, $p<0.01, F_{(39,702)}=3.98$; BL nucleus, $p<0.01$, $\left.F_{(39,390)}=2.79\right]$, indicating that the lesion-related firing losses occurred in specific post-CS $10 \mathrm{msec}$ intervals.

\section{Excitatory $T I A$}

All areas of rabbits in the control group developed traininginduced neuronal excitation, i.e., increased neuronal firing to the $\mathrm{CS}+$ and $\mathrm{CS}-$ compared with firing to these stimuli during pretraining with tone and unpaired US presentations. Excitatory TIA did not develop in any monitored area in rabbits with electrolytic MG nuclear lesions.

This was indicated for the AV nucleus by a significant interaction of group, training stage, and stimulus factors $\left[p<0.05 ; F_{(3,42)}\right.$ $=3.13$. Simple effect tests indicated that the AV thalamic neurons of rabbits in the control group exhibited increased average $\mathrm{CS}+$ elicited discharge magnitudes relative to pretraining, during the session of criterion attainment ( $p<0.05$; Fig. 4$)$, but not in other sessions. No significant excitatory TIA was observed for the lesion group in any session.

The analysis of the data of the MD nucleus yielded a significant interaction of the group, training stage, and recording interval factors $\left[p<0.01 ; F_{(117,1404)}=1.40\right]$. Neurons of the MD thalamic nucleus in the control group exhibited maximal discharge increases during the session of criterion attainment. This effect occurred after CS onset at 70, 80, 100-120, 150-270, 290-320, $340-350,370-380$, and $400 \mathrm{msec}(p<0.05$; Fig. 5). No significant excitatory TIA was observed for the lesion group in any session.

A significant interaction of the group, training stage, and recording interval factors occurred for the anterior cingulate cortex $\left[p<0.01 ; F_{(117,2106)}=1.46\right]$. The anterior cingulate cortical neurons of controls exhibited significant increases in the average discharge magnitudes relative to pretraining during the session of first significant behavioral discrimination. This effect occurred 40, 270, 300, 340, 360, and 390 msec after CS onset ( $p<0.05$; Fig. 6). No significant excitatory TIA was observed for the rabbits with lesions in any session.

The analysis of the BL amygdalar neuronal data yielded a significant interaction of the group, training stage, and recording interval factors $\left[p<0.01 ; F_{(117,1170)}=1.64\right]$. The largest average discharge increments were exhibited by the neuronal records of the controls during the session of first significant behavioral discrimination. This effect occurred 60, 80-210, and 260-400 msec after CS onset ( $p<0.05$; Fig. 7). No significant excitatory TIA was observed for the rabbits with lesions.

\section{Discriminative TIA}

All areas in the controls developed training-induced neuronal discrimination, i.e., more neuronal firing to the $\mathrm{CS}+$ than to the CS-. Development of discriminative TIA was blocked in all areas in the rabbits with lesions. A significant interaction of the group, training stage, and stimulus factors occurred for the AV nucleus $\left[p<0.05 ; F_{(3,42)}=3.13\right]$. Simple effect tests indicated that the AV thalamic neurons in the control group exhibited discriminative TIA during the session of criterion attainment $(p<0.05$; Fig. 4). No significant discriminative TIA was observed for the lesion group in any session.

A significant interaction of the group, stimulus, and recording interval factors in the analysis of the MD thalamic neuronal data $\left[p<0.01 ; F_{(39,468)}=1.58\right]$ demonstrated significant discriminative TIA (pooled over sessions) in the control group 40-70, 130, 200, 330-350, and $400 \mathrm{msec}$ after CS onset ( $p<0.05$; Fig. 5). Discriminative TIA occurred in the lesion group in only one post-CS interval, $30 \mathrm{msec}$ after CS onset.

A significant interaction of the group, stimulus, and recording interval factors in the analysis of the anterior cingulate cortical data $\left[p<0.01 ; F_{(39,702)}=2.92\right]$ showed discriminative TIA 


\section{AV NUCLEUS}

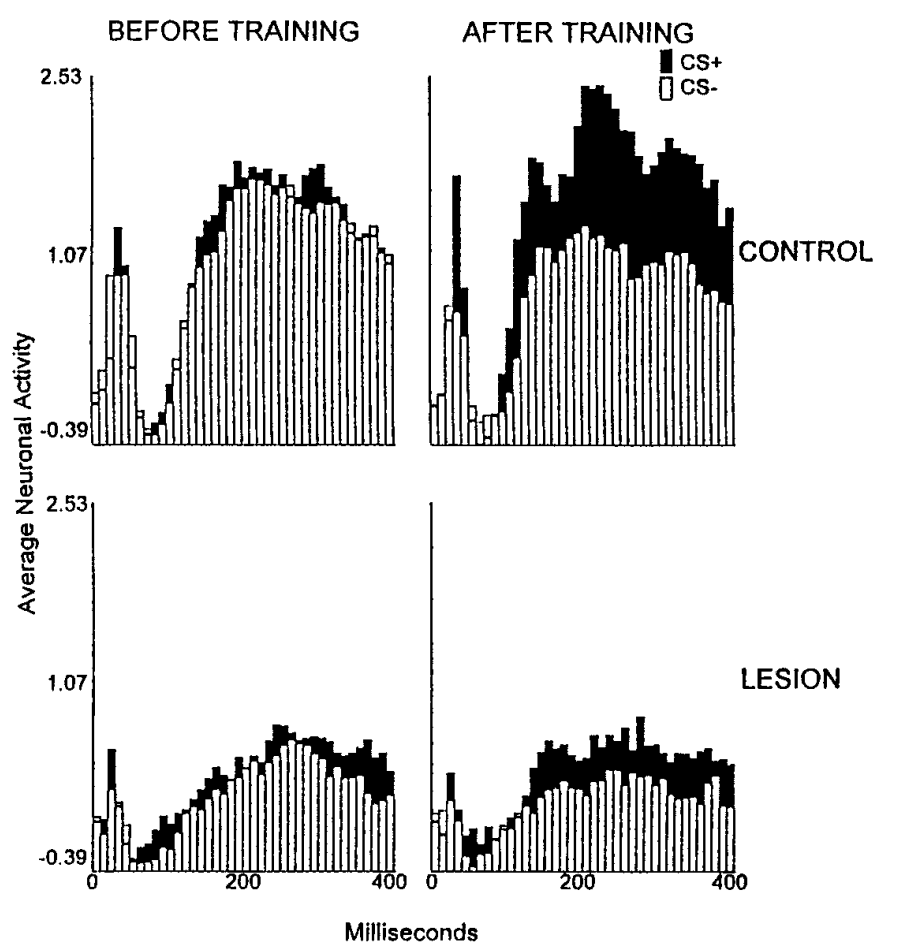

Figure 4. Average multiunit neuronal activity of the anterior ventral thalamic nucleus after the onset of the CS+ (filled bars) and CS- (open bars) in the control group ( $n=8$; top row) and the electrolytic lesion group $(n=8$; bottom row) during preliminary training (BEFORE TRAINING) with unpaired $C S$ and foot shock presentations and during the session in which criterion was attained (AFTER TRAINING), or in a matching session for those rabbits that did not reach criterion. The neuronal data are plotted in 40 consecutive $10 \mathrm{msec}$ intervals after the onset of the conditional stimuli, which occurred at the leftmost $(0)$ value on the abscissa. The plotted values are normalized relative to a $300 \mathrm{msec}$ prestimulus baseline (see Materials and Methods).

(pooled over sessions) in the controls 40-60, 100, 180, 210, 270, and 400 msec after CS onset $(p<0.05$; Fig. 6). No significant discriminative TIA was observed in the rabbits with lesions.

A significant interaction of the group, stimulus, and recording interval factors in the analysis of the $\mathrm{BL}$ amygdalar neuronal data $[p<0.01 ; F(39,390)=1.45]$ showed discriminative TIA pooled over sessions in the control group 90-100, 150-210, 230-250, $320-340,360-370$, and 390 msec after CS onset $(p<0.05$; Fig. $7)$. Again, no significant discriminative TIA was observed for the lesion group.

\section{Neuronal data, ibotenic acid lesions \\ Evoked activity, AV thalamic neurons}

The average CS-elicited AV thalamic neuronal discharges in rabbits with ibotenic acid lesions were significantly reduced, relative to the discharges in controls, during pretraining with tones alone $\left[p<0.01 ; F_{(39,429)}=3.01\right]$.

\section{Excitatory and discriminative TIA in the AV nucleus}

Despite the aforementioned reduction of elicited neuronal discharges during pretraining, normative excitatory TIA did develop in the AV nucleus in rabbits with ibotenic acid lesions during the session of criterion attainment $\left[p<0.01 ; F_{(117,1287)}=1.69\right]$. However, the magnitude of discriminative TIA during perfor-
MD NUCLEUS

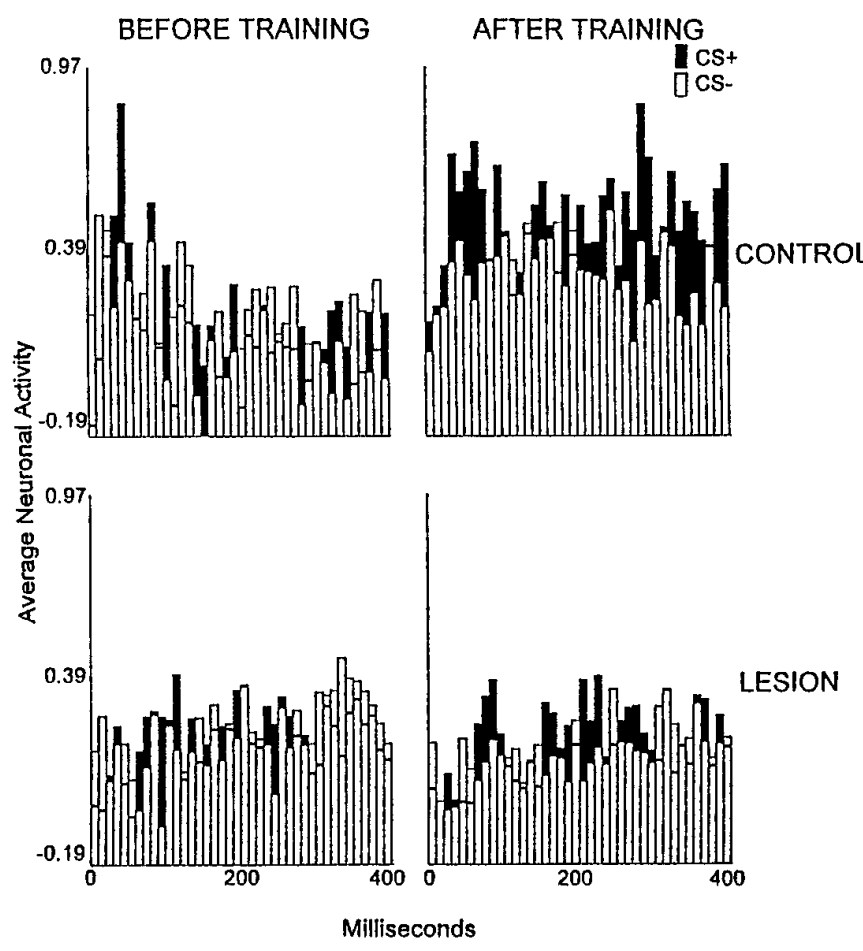

Figure 5. Average multiunit neuronal activity of the medial dorsal thalamic nucleus during the first $400 \mathrm{msec}$ after the onset of the CS+ (filled bars) and CS - (open bars) in the control group $(n=9$; top row) and the electrolytic lesion group (bottom row) during unpaired CS and foot shock presentations (BEFORE TRAINING) and during the session in which criterion was attained ( $n=6 ; A F T E R T R A I N I N G)$ or a matching session for rabbits that did not reach criterion. The neuronal data are plotted in 40 consecutive $10 \mathrm{msec}$ intervals after the onset of the conditional stimuli, which occurred at the leftmost $(0)$ value on the abscissa. The plotted values are normalized relative to a $300 \mathrm{msec}$ prestimulus baseline (see Materials and Methods).

mance at criterion was significantly reduced in the rabbits with ibotenic acid lesions relative to controls $\left[p<0.01 ; F_{(117,1287)}=\right.$ 1.69]. Simple effect tests showed that the average firing frequency after CS+ presentation in the control group exceeded significantly the average firing frequency after CS - presentation in 29 intervals after CS onset $(p<0.05)$. However, this difference was found for only nine intervals in the lesion group.

The small number of neuronal records precluded analysis of the effects of ibotenic acid lesions on neuronal data of the remaining areas.

\section{DISCUSSION}

\section{Summary of findings and conclusions}

Past work has shown that neurons in cingulate cortex and in the reciprocally interconnected anterior and MD nuclei of thalamus are importantly involved in mediation of discriminative avoidance learning, wherein rabbits step in response to a tone (CS+) to avoid a foot shock, and they ignore a different tone $(\mathrm{CS}-)$ not predictive of foot shock. Lesions in these areas severely impaired learning, and neuronal activity recorded during acquisition exhibited massive associative plasticity, in the form of excitatory and discriminative TIA as described above.

This study was designed to establish whether the MG nucleus, 
ANTERIOR CINGULATE CORTEX

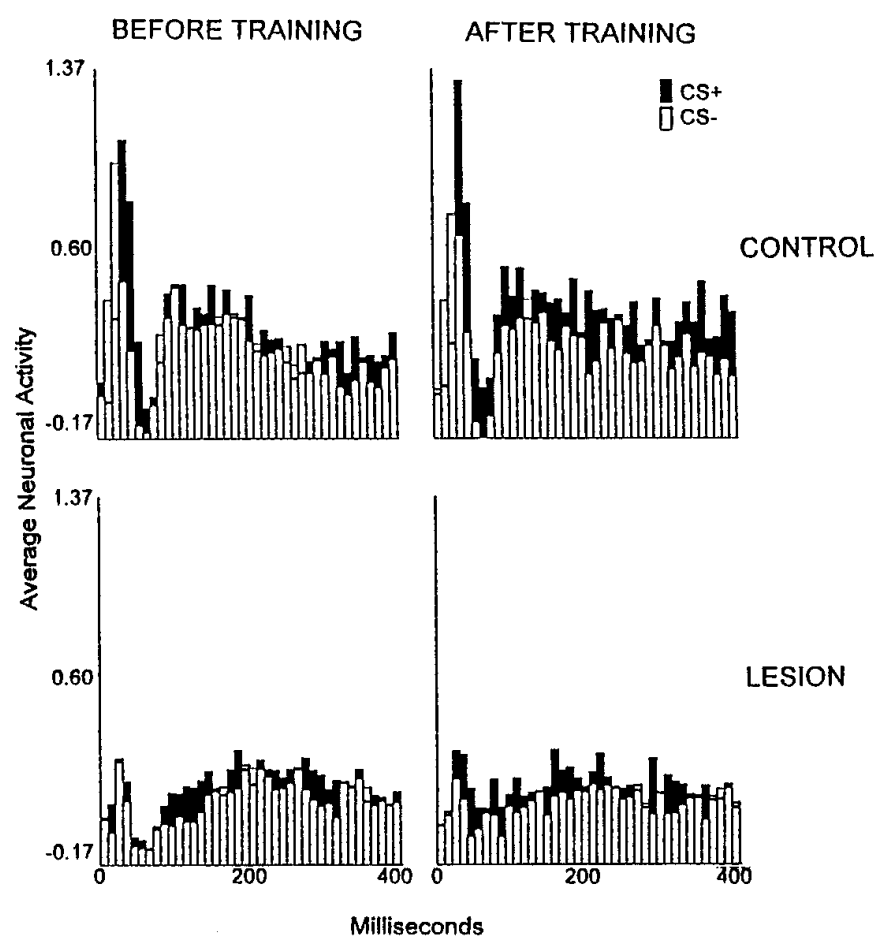

Figure 6. Average multiunit neuronal activity of the anterior cingulate cortex (area 24b) during the first $400 \mathrm{msec}$ after the onset of the CS+ (filled bars) and CS- (open bars) in the control group $(n=14$; top row $)$ and the electrolytic lesion group ( $n=7$; bottom row) during unpaired CS and foot shock presentations (BEFORE TRAINING) and during the session in which first significant discrimination was attained (AFTER TRAINING) or a matching session for those rabbits that did not reach first significant discrimination. The neuronal data are plotted in 40 consecutive $10 \mathrm{msec}$ intervals after the onset of the conditional stimuli, which occurred at the leftmost $(0)$ value on the abscissa. The plotted values are normalized relative to a $300 \mathrm{msec}$ prestimulus baseline (see Materials and Methods).

the thalamic relay for audition, is a necessary component of the circuitry that mediates discriminative avoidance learning. This would be the case if, for example, the neurons of the MG nucleus transmit auditory sensory information used for task-relevant associative coding in the cingulate cortex and limbic thalamus. The alternative possibility is that cingulate cortex and limbic thalamus receive auditory sensory information via routes that do not traverse the MG nucleus.

Beyond sensory transmission, MG nuclear neurons may perform associative processing essential for discriminative avoidance learning. Associative neuronal activity in the form of discriminative TIA has been documented in the MG nucleus during discriminative avoidance learning and in other forms of aversively motivated learning (see the introductory remarks).

The present results showed that discriminative avoidance learning was impaired severely and cingulothalamic traininginduced neuronal activity was abolished in rabbits with lesions. Thus, the integrity of the MG nucleus is required for discriminative avoidance learning as well as learning-relevant associative plasticity in the BL nucleus of the amygdala and in the aforementioned cingulothalamic areas.

\section{BL NUCLEUS}

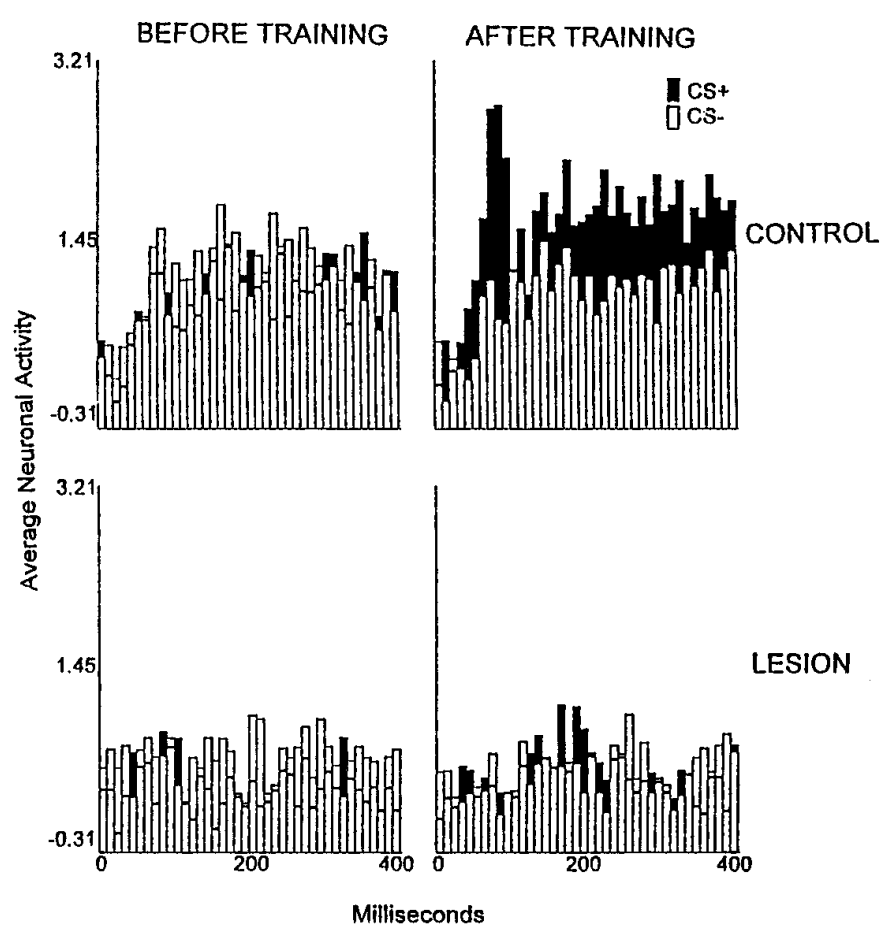

Figure 7. Average multiunit neuronal activity of the basolateral amygdalar nucleus during the first $400 \mathrm{msec}$ after the onset of the CS+ (filled bars) and CS- (open bars) in the control group $(n=6$; top row) and the electrolytic lesion group ( $n=6$; bottom row) during unpaired CS and foot shock presentations (BEFORE TRAINING) and during the session in which the first significant discrimination was attained (AFTER TRAIN$I N G)$, or a matching session for rabbits that did not exhibit a significant discrimination. The neuronal data are plotted in 40 consecutive $10 \mathrm{msec}$ intervals after the onset of the conditional stimuli, which occurred at the leftmost $(0)$ value on the abscissa. The plotted values are normalized relative to a $300 \mathrm{msec}$ prestimulus baseline (see Materials and Methods).

\section{Spared and deleted neuronal activity in rabbits with lesions}

Firing of BL amygdalar neurons in response to the CS+ and $\mathrm{CS}-$ before and during training was completely abolished in rabbits with lesions. This finding is, to our knowledge, the first demonstration that neurons of the MG and peri-MG nuclei, which send axonal projections to the amygdala (LeDoux et al., 1990), are essential for acoustically triggered activation of amygdalar neurons during learning in behaving subjects. Surprisingly, there was no significant reduction of the elicited discharges of the MD thalamic nucleus in rabbits with MG lesions. Moreover, although attenuated significantly, the firing of neurons in anterior cingulate cortex and in the AV thalamic nucleus nevertheless occurred in response to the auditory conditional stimuli before and during avoidance learning in rabbits with MG nuclear lesions.

It is possible that residual auditory transmission to limbic thalamus and cingulate cortex in rabbits with MG nuclear lesions was a product of spared MG cells. However, this possibility is opposed by the finding that the lesions were sufficiently large to eliminate all auditory transmission to $\mathrm{BL}$ amygdalar neurons. These results favor the hypothesis that auditory information can attain the limbic thalamus and cingulate cortex via routes that do not traverse the MG nucleus. Extrageniculate projections could originate in areas such as the pontine reticular formation (Ste- 
riade et al., 1988; Kandler and Herbert, 1991) and the cochlear nucleus (Woody et al., 1991).

\section{Are the lesion-induced deficits sensory or associative?}

The data in hand do not permit a definitive answer to this question. However, the finding that the MG nucleus may not be the sole source of auditory transmission to limbic thalamus and cingulate cortex favors the hypothesis that the deficits in learning and in neuronal plasticity were attributable at least in part to a disturbance of the associative neuronal processes of MG neurons. This hypothesis also receives support from the finding that the only MG nuclear damage found to be significantly correlated with performance of the learned response was damage in the medial division of the MG nucleus, i.e., the division in which associative neuronal changes are exhibited during learning. These findings are consistent with the generally held view that sensory coding in the MG nucleus is performed primarily by neurons of the ventral division of the MG nucleus, which send axons to primary and secondary areas of auditory cortex, but not to the amygdala. Although the lesions of this study undoubtedly interfered with these neurons, the impaired sensory functions may not be essential for discriminative avoidance learning, because these areas of the MG nucleus and their auditory projection fields do not appear to be essential for other forms of acoustically cued aversive conditioning (Teich et al., 1988; Campeau and Davis, 1995).

\section{Synaptic origins of TIA}

The present data pertain to the long-standing question concerning whether the amygdala or the MG nucleus is the site of the biophysical coding (e.g., synaptic efficacy change) that mediates associative plasticity and behavioral learning in aversive conditioning paradigms. Both of these regions receive requisite convergent input of acoustic and nociceptive information that could foster synaptic changes. However, the more peripheral position of the $\mathrm{MG}$ nucleus in relation to sensory transmission and the present observation that discriminative TIA in the amygdala was abolished in subjects with MG nuclear lesions would seem to favor the view that the MG nucleus is a site of the biophysical coding. On the other hand, temporary lesions of the amygdala administered at the outset of discriminative avoidance training permanently blocked development of MG nuclear discriminative TIA (Poremba, 1995), a result which suggests that the integrity of the amygdala is essential for training-induced discriminative plasticity in the MG nucleus. We would therefore suggest that associative processes of MG nuclear and amygdalar neurons are mutually interdependent; both areas must be intact if their neurons are to exhibit discriminative TIA.

\section{Implications for functional organization of the learning-relevant circuitry}

The notion that amygdalar and MG neurons form an integral unit is consistent with the remarkable similarity of the TIA documented in the BL amygdala and the medial MG nucleus. Statistically significant discriminative TIA developed in both areas during the first conditioning session, the magnitude of the effect reached maximum early in training, and the effect declined in both areas as the rabbits reached the acquisition criterion (Gabriel et al., 1990; Maren et al., 1991). In contrast, neurons in posterior cingulate cortex, the AV thalamic nucleus and the MD thalamic nucleus did not exhibit maximal discriminative TIA until criterion was reached (for review, see Gabriel, 1993).

In addition to the highly similar acquisition functions for TIA, both MG and amygdalar lesions had a similar impact on behavior and on cingulothalamic TIA. These similarities suggest that the medial MG nucleus and the relevant areas of the amygdala are parts of a distinct functional circuit. We have adopted the designation afferent limb for this component of the circuit for discriminative avoidance learning. It is further proposed that the activity of afferent limb circuit neurons is critically involved in the production of TIA in cingulate cortex and limbic thalamus.

Neurons in the anterior cingulate cortex exhibited discriminative TIA during early training trials, as in the afferent limb circuit, and anterior cingulate neurons receive direct synaptic input from neurons in the BL amygdala. These facts suggest that anterior cingulate cortex should be accorded membership in the afferent limb. This possibility is, however, not favored by the effects of anterior cingulate cortical lesions, which mildly retard behavioral acquisition (Gabriel et al., 1991a) but do not block it, as do afferent limb circuit lesions.

Neurons in the posterior cingulate cortex and in the reciprocally interconnected anterior ventral thalamic nucleus exhibit a unique, late-developing TIA, and lesions in these areas reduce performance efficiency only during criterial and postcriterial training and leave behavioral acquisition unaffected. Neurons of the MD nucleus exhibit low-amplitude early discriminative TIA and large-amplitude late discriminative TIA. MD lesions alone mildly retard acquisition, and they also impair performance of well trained rabbits.

These results suggest that specific cingulothalamic circuits are involved preferentially in mediating particular stages (early or late) of behavioral acquisition. In contrast, the afferent limb circuit is essential for initiating learning-relevant plasticity in the early and late discriminating components of the cingulothalamic circuitry. It is thus proposed that the cingulothalamic areas constitute a functional circuit that is separate and distinct from the afferent limb.

The present data are compatible with the hypothesis that the afferent limb circuit is the substrate of the conditioned emotional response of fear, as postulated by others on the basis of studies of the neural substrates of classical Pavlovian conditioning (Davis, 1992; Helmstetter, 1992; Fanselow and Kim, 1994; LeDoux, 1995). We have proposed elsewhere that the cingulothalamic TIA is a neural code for retrieval of goal-directed instrumental behavior (Gabriel et al., 1991b; Steinmetz et al., 1991; Freeman et al., 1996; Gabriel et al., 1996). Retrieval occurs, putatively, as a result of the interactions of cingulate cortical and striatal neurons involved respectively in coding of associative significance of cues and in the priming and execution of goal-directed, whole-body and limb movements.

The present findings indicate that the elaboration of conditioned fear in the afferent limb circuit is necessary for the earlyand late-developing cingulothalamic TIA. In short, associative, fear-related processes of the afferent limb circuit are essential for the establishment of the cingulothalamic neural significance code for retrieval of instrumental learned responses. This establishment could occur by way of the direct axonal projections from the $\mathrm{BL}$ amygdalar neurons to the anterior cingulate cortex and MD thalamic nucleus and via projections of central amygdalar neurons to brainstem tegmental and mamillary neurons that modulate the anterior thalamus (Price et al., 1987).

Several theories postulate that instrumental learning is a product of two processes: (1) Pavlovian classical conditioning of emotional responses, and (2) operant conditioning of instrumental behavior (Miller and Konorski, 1928; Pavlov, 1932; Skinner, 1938; Mowrer, 1947; Spence, 1956; Rescorla and Solomon, 1967; Trap- 
old and Overmier, 1972). The present finding that afferent limb emotional conditioning processes are essential for the cingulothalamic changes that support instrumental avoidance learning provides the first putative identification of separate neuroanatomical substrates of the two processes, as well as anatomical and physiological links between them. This suggested division of function is also supported by the demonstrations that (1) acquisition and maintained performance of aversively motivated Pavlovian conditioned responses (CRs) require an intact amygdala (Weisz et al., 1992; Lee et al., 1996; Maren et al., 1996); (2) acquisition and performance of at least one variety of aversively motivated Pavlovian $\mathrm{CR}$, the eye blink $\mathrm{CR}$, do not require intact cingulothalamic circuitry (Gabriel et al., 1996); and (3) the contribution of the amygdala to aversively motivated instrumental learned responses diminishes as experience accumulates in a given task (Parent et al., 1992; Roozendaal et al., 1993; Poremba and Gabriel, 1995).

\section{REFERENCES}

Applegate CD, Frysinger RC, Kapp BS, Gallagher M (1982) Multiple unit activity recorded from amygdala central nucleus during Pavolvian heart rate conditioning in rabbit. Brain Res 234:251-262.

Birt D, Olds M (1981) Associative response changes in lateral midbrain tegmentum and medial geniculate during differential appetitive conditioning. J Neurophysiol 46:1039-1055.

Blanchard DC, Blanchard RJ (1972) Innate and conditioned reactions to threat in rats with amygdaloid lesions. J Comp Physiol Psychol 81:281-290.

Brogden WJ, Culler FA (1936) A device for motor conditioning of small animals. Science 83:269.

Buchwald WJ, Holstein SB, Weber DS (1973) Multiple unit recording: technique, interpretation, and experimental applications. In: Bioelectric recording techniques. A. Cellular processes and brain potentials (Thomson RF, Patterson MM, eds), pp 202-242. New York: Academic.

Campeau S, Davis M (1995) Involvement of subcortical and cortical afferents to the lateral nucleus of the amygdala in fear conditioning measured with fear-potenitated startle in rats trained concurrently with auditory and visual conditioned stimuli. J Neurosci 15:2312-2327.

Davis M (1986) Pharmacological and anatomical analysis of fear conditioning using the fear-potentiated startle paradigm. Behav Neurosci 100:814-824.

Davis M (1992) The role of the amygdala in fear and anxiety. Annu Rev Neurosci 15:353-376.

Donovick PJ (1974) A metachromatic stain for neural tissue. Stain Technol 49:49-51.

Edeline JM (1990) Frequency-specific plasticity of single unit discharges in the rat medial geniculate body. Brain Res 529:109-119.

Edeline JM, Weinberger NM (1992) Associative retuning in the thalamic source of input to the amygdala and auditory cortex: receptive field plasticity in the medial division of the medial geniculate body. Behav Neurosci 106:81-105.

Fanselow MS, Kim JJ (1994) Acquisition of contextual Pavlovian fear conditioning is blocked by application of an NMDA receptor antagonist D,L-2-amino-5-phosphonovaleric acid to the basolateral amygdala. Behav Neurosci 108:210-212.

Freeman Jr JH, Cuppernell C, Flannery K, Gabriel M (1996) Contextspecific multi-site cingulate cortical, limbic thalamic and hippocampal neuronal activity during concurrent discriminative approach and avoidance training in rabbits. J Neurosci 16:1538-1549.

Freeman Jr JH, Weible A, Rossi J, Gabriel M (1997) Entorhinal cortex lesions disrupt context processing and alter amygdalar and cingulate cortical neuronal activity during extinction of discriminative avoidance learning. Exp Brain Res 115:445-457.

Fox CA, Eichman J (1959) A rapid method for locating intracerebral electrode tracks. Stain Technol 34:39-42.

Gabriel M (1990) Functions of anterior and posterior cingulate cortex during avoidance learning in rabbits. In: Progress in brain research, Vol 85 (Uylings HBM, Van Eden CG, De Bruin JPC, Corner MA, Feeustra MGP, eds), pp 467-483. Amsterdam: Elsevier.

Gabriel M (1993) Discriminative avoidance learning: a model system. In: Neurobiology of cingulate cortex and limbic thalamus: a compre- hensive handbook (Vogt BA, Gabriel M, eds), pp 478-523. Boston: Birkhauser.

Gabriel M, Saltwick SE, Miller J (1975) Conditioning and reversal of short-latency multiple-unit responses in the rabbit medial geniculate nucleus. Science 189:1108-1109.

Gabriel M, Miller J, Saltwick SE (1976) Multiple unit activity of the rabbit medial geniculate nucleus in conditioning, extinction, and reversal. Physiol Psychol 4:124-134.

Gabriel M, Lambert RW, Foster K, Orona E, Sparenborg S, Maiorca RR (1983) Anterior thalamic lesions and neuronal activity in the cingulate and retrosplenial cortices during discriminative avoidance behavior in rabbits. Behav Neurosci 97:675-696.

Gabriel M, Poremba A, Ellison-Perrine C, Miller JD (1990) Brainstem mediation of learning and memory. In: Brainstem mechanisms of behavior (Klemm WR, Vertes RP, eds) pp 269-313. New York: Wiley.

Gabriel M, Kubota Y, Sparenborg S, Straube K, Vogt BA (1991a) Effects of cingulate cortical lesions on avoidance learning and traininginduced unit activity in rabbits. Exp Brain Res 86:585-600.

Gabriel M, Vogt BA, Kubota Y, Poremba A, Kang E (1991b) Trainingstage related neuronal plasticity in limbic thalamus and cingulate cortex during learning: a possible key to mnemonic retrieval. Behav Brain Res 46:175-185.

Gabriel M, Kang E, Poremba A, Kubota Y, Allen MT, Miller DP, Steinmetz JE (1996) Neural substrates of discriminative avoidance learning and classical eyeblink conditioning in rabbits: a double dissociation. Behav Brain Res 82:23-30.

Gentile CG, Jarrell TW, Teich A, McCabe PM, Schneiderman N (1986) The role of amygdaloid central nucleus in the retention of differential Pavlovian conditioning of bradycardia in rabbits. Behav Brain Res 20:263-273.

Girgis M, Shih-Chang W (1981) A new stereotaxic atlas of the rabbit brain. St. Louis: Green.

Helmstetter FJ (1992) Contribution of the amygdala to learning and performance of conditional fear. Physiol Behav 51:1271-1276.

Hitchcock JM, Davis M (1987) Fear-potentiated startle using an auditory conditioned stimulus: effect of lesions of the amygdala. Physiol Behav 39:403-408.

Huynh H, Feldt LS (1976) Estimation of the Box correction for degrees of freedom from sample data in randomized block and split-plot designs. J Educ Stat 1:69-82.

Iwata J, LeDoux JE, Meeley MP, Arneric S, Reis DJ (1986) Intrinsic neurons in the amygdaloid field projected to by the medial geniculate body mediate emotional responses conditioned to acoustic stimuli. Brain Res 383:195-214.

Jarrell TW, Gentile CG, McCabe PM, Schneiderman N (1986) The role of the medial geniculate region in differential Pavlovian conditioning of bradycardia in rabbits. Brain Res 374:126-136.

Kandler K, Herbert H (1991) Auditory projections from the cochlear nucleus to pontine and mesencephalic reticular nuclei in the rat. Brain Res 562:230-242.

Kapp BS, Frysinger RC, Gallagher M, Haselton JR (1979) Amygdala central nucleus lesions: effect on heart rate conditioning in the rabbit. Physiol Behav 23:1109-1117.

Kubota Y, Gabriel M (1995) Studies of the limbic comparator: limbic circuit training-induced unit activity and avoidance behavior in rabbits with anterior dorsal thalamic lesions. Behav Neurosci 109:258-277.

Kubota Y, Wolske M, Poremba A, Kang E, Gabriel M (1996) Stimulusrelated and movement-related single-unit activity in rabbit cingulate cortex and limbic thalamus during performance of discriminative avoidance behavior. Brain Res 721:22-38.

LeDoux JE (1995) Emotion: clues from the brain. Annu Rev Psychol 46:209-235.

LeDoux JE, Ruggiero DA, Reis DJ (1985) Projections to the subcortical forebrain from anatomically defined regions of the medial geniculate body in the rat. J Comp Neurol 242:182-213.

LeDoux JE, Iwata J, Pearl D, Reis DJ (1986a) Disruption of auditory but not visual learning by destruction of intrinsic neurons in the medial geniculate body of the rat. Brain Res 371:395-399.

LeDoux JE, Sakaguchi A, Iwata J, Reis DJ (1986b) Interruption of projections from the medial geniculate body to an archineostriatal field disrupts the classical conditioning of emotional responses to acoustic stimuli. Neuroscience 17:615-627.

LeDoux JE, Iwata J, Cicchetti P, Reis DJ (1988) Different projections of the central amygdaloid nucleus mediate autonomic and behavioral correlates of conditioned fear. J Neurosci 8:2517-2529. 
LeDoux JE, Farb C, Ruggiero DA (1990) Topographic organization of neurons in the acoustic thalamus that project to the amygdala. J Neurosci 10:1043-1054.

Lee Y, Walker D, Davis M (1996) Lack of a temporal gradient of retrograde amnesia following NMDA-induced lesions of the basolateral amygdala assessed with the fear-potentiated startle paradigm. Behav Neurosci 110:836-839.

Lennartz RC, Weinberger NM (1994) A comparison of nonspecific and nictitating membrane conditioned responses: additional support for two-factor theories. Psychobiology 22:5-15.

Maren S, Fanselow MS (1996) The amygdala and fear conditioning: has the nut been cracked? Neuron 16:237-256.

Maren S, Poremba A, Gabriel M (1991) Basolateral amygdaloid multiunit neuronal correlates of discriminative avoidance learning in rabbits. Brain Res 549:311-316.

Maren S, Aharonoz G, Fanselow MS (1996) Retrograde abolition of conditional fear after excitotoxic lesions in the basolateral amygdala of rats: absence of a temporal gradient. Behav Neurosci 110:718-726.

McCabe PM, McEchron MD, Green EJ, Schneiderman N (1993) Electrolytic and ibotenic acid lesions of the medial subnucleus of the medial geniculate prevent the acquisition of classically conditioned heart rate to a single acoustic stimulus in rabbits. Brain Res 619:291-298.

McEchron MD, McCabe PM, Green EJ, Llabre MM, Schneiderman N (1995) Simultaneous single unit recording in the medial nucleus of the medial geniculate nucleus and amygdaloid central nucleus throughout habituation, acquisition, and extinction of the rabbit's classically conditioned heart rate. Brain Res 682:157-166.

McGaugh J, Cahill L, Parent MB, Mesches MH, Coleman-Mesches K, Salinas JA (1995) Involvement of the amygdala in the regulation of memory storage. In: Plasticity in the central nervous system: learning and memory (McGaugh JL, Bermudez-Rattoni F, Prado-Alcala RA, eds), pp 17-39. Mahwah, NJ: Erlbaum.

Miller S, Konorski J (1928) Sur une forme particuliere des reflexes conditionnels. C R Seances Soc Biol Fil 99:1155-1157.

Mowrer OH (1947) On the dual nature of learning - a reinterpretation of "conditioning" and "problem-solving." Harv Educ Rec 17:102-148.

Muramuto K, Ono T, Nishijo H, Fukuda M (1993) Rat amygdaloid neuron responses during auditory discrimiation. Neuroscience 52:621-636.

Nishijo H, Ono T, Nishino H (1988) Single neuronal responses in amygdala of alert monkey during complex sensory stimulation with effective significance. J Neurosci 8:3570-3583.

Olds J, Disterhoft J, Segal M, Kornblith DL,. Hirsh R (1972) Learning centers of rat brain mapped by measuring latencies of conditioned unit responses. J Neurophysiol 25:202-219.

Parent MB, Carlos, T, McGaugh JL (1992) Increased training in an aversively motivated task attenuates the memory-impairing effects of posttraining N-methyl-D-aspartate-induced amygdala lesions. Behav Neurosci 106:789-797.

Pascoe JP, Kapp BS (1985) Electrophysiological characteristics of amydaloid central nucleus neurons during Pavlovian fear conditioning in the rabbit. Behav Brain Res 16:117-133.

Pavlov IP (1932) The reply of a physiologist to psychologists. Psychol Rev 39:91-127.

Poremba A (1995) Neural substrates of avoidance behavior: The afferent limb. PhD thesis, University of Illinois, Urbana.

Poremba A, Gabriel M (1993) Lesions of the medial geniculate nucleus, avoidance learning and limbic system training-induced neuronal activity in rabbits. Soc Neurosci Abstr 19:802.

Poremba A, Gabriel M (1997) Amygdalar lesions block discriminative avoidance learning and cingulothalamic training-induced neuronal plasticity in rabbits. J Neurosci 17:5237-5244.

Price JL, Russchen R T, Amaral D G (1987) The limbic region II: The amygdaloid complex. In: Handbook of chemical neuroanatomy, Vol 5,
Integrated systems of the CNS, Part I, Hypothalamus, hippocampus, amygdala, retina (Bjorklund A, Hokfelt T, Swanson LW, eds), pp 279-338. Amsterdam: Elsevier.

Quirk GJ, Repa C, LeDoux JE (1995) Fear conditioning enhances shortlatency auditory responses of lateral amygdala neurons: parallel recordings in the freely behaving rat. Neuron 15:1029-1039.

Rescorla RA (1967) Pavlovian conditioning and its proper control procedures. Psychol Rev 74:71-80.

Rescorla RA, Solomon RL (1967) Two-process learning theory: Relationships between Pavlovian conditioning and instrumental learning. Psychol Rev 74:151-182.

Roozendaal B, Koolhaas JM, Bohus B (1993) The central amygdala is involved in conditioning but not in retention of active and passive shock avoidance behavior in male rats. Behav Neural Biol 59:143-149.

Ryugo DK, Weinberger NM (1978) Differential plasticity of morphologically distinct neuron populations in medial geniculate body of the cat during classical conditioning. Behav Biol 22:275-301.

Sananes CB, Davis M (1992) N-Methyl-D-aspartate lesions of the lateral and basolateral nuclei of the amygdala block fear-potentiated startle and shock sensitization of startle. Behav Biol 22:275-301.

Skinner BF (1938) The Behavior of organisms. New York: Appleton-Century-Crofts.

Spence KW (1956) Behavior theory and conditioning. New Haven, CT: Yale UP.

Spevack AA, Campbell CT, Drake L (1975) Effects of amygdalectomy on habituation and CER in rats. Physiol Behav 15:199-207.

Steinmetz J, Sears LL, Gabriel M, Kubota Y, Poremba A, Kang E (1991) Cerebellar interpositus nucleus lesions disrupt classical nictitating membrane conditioning but not discriminative avoidance learning in rabbits. Behav Brain Res 45:71-80.

Steriade M, Pare D, Parent A, Smith Y (1988) Projections of cholinergic and non-cholinergic neurons of the brainstem core to relay and associational thalamic nuclei in the cat and macaque monkey. Neuroscience 25:47-67.

Teich AH, McCabe PM, Gentile CG, Jarrell TW, Winters RW, Liskowsky DR, Schneiderman NS (1988) Role of auditory cortex in the acquisition of differential heart rate conditioning. Physiol Behav 44:405-412.

Trapold MA, Overmier JB (1972) The second learning process in instrumental learning. In: Classical conditoining II: current research and theory (Black AH, Prokasy WF, eds), pp 427-452. New York: Appleton-Centruy-Crofts.

Umemoto M, Olds ME (1975) Effects of chlordiazepoxide, diazepam and chlorpromazine on conditioned emotional behavior and conditioned neuronal activity in limbic, hypothalamic and geniculate regions. Neuropharmacology 14:413-425.

Walker HM, Lev J (1953) Statistical inference. New York: Holt.

Weinberger NM (1982) Sensory plasticity and learning: the magnocellular medial geniculate nucleus of the auditory system. In: Conditioning: representation of involved neural function (Woody CD, ed), pp 697-710. New York: Plenum.

Weisz DJ, Harden DG, Xiang Z (1992) Effects of amygdala lesions on reflex facilitation andconditioned response acquisition during nictitating membrane response conditioning in rabbit. Behav Neurosci 106:262-273.

Winer BJ (1962) Statistical principles in experimental design. New York: McGraw-Hill.

Winer JA, Morest DK (1983) The medial division of the medial geniculate body of the cat: Implications for thalamic organization. J Neurosci 3:2629-2651.

Woody CD, Gruen E, Melamed O, Chizhevsky V (1991) Patterns of unit activity in the rostral thalamus of cats related to short-latency discrimination between different auditory stimuli. J Neurosci 11:48-58. 